\title{
RE-GENDERING OF THE WORKFORCE: WOMEN AND MEN IN "NON-TRADITIONAL" OCCUPATIONS AND INDUSTRIES
}

\author{
Robert Didham
}

Statistics New Zealand and Waikato University

\begin{abstract}
Many occupations and industries have traditionally remained the preserve of either men or women. In recent years, a range of campaigns and policies have focussed on equity for women and equality of opportunity for both men and women in the work force. This paper looks at some of the background, ongoing discrimination and the forces acting for and against gender balance which has brought about some re-gendering of occupations.
\end{abstract}

\section{Introduction}

This paper grew out of two pieces of apparently unrelated work. As part of the commemoration of World War 1 I was involved in looking at the demographic impact of the war and how this related to wider social and political histories. Then as part of the work around the recovery of Christchurch following the earthquakes, I was involved with looking at population changes and changes in the labour market. Parallels between the two events stand out and raised a question which is related to wider discussions around gender relations, gender equality policies, anti-agediscrimination policy and occupation, and changes in the composition of workforces as industry changes.

Purpose of this paper is not to provide answers so much as to provoke questions that need further work. This is a very fertile field for historical research, demographic and sociological study and continuing development of effective policy initiatives. However, we need to answer preliminary questions in order to place the debate in context.

The terms occupation and industry refer to different things, but in this paper the terms are not treated with rigour for simplicity, though this is an aspect that would reward further thought. Occupations map differently across industries, and the way they do so has changed over time. This becomes important when we are dealing with information that comes from different collection regimes, as we are if we look at two periods a century apart. The history of the relationship between occupation and industry data is fascinating. Prior to 1921 the emphasis was on occupation with industry as supplementary information. Conference of Statistical Officers of the British Empire in 1920 decreed they should have equal weight, each with their own classification. 
But by the mid-1950s the situation reversed and occupation data became rudimentary and but industry very detailed. To make it worse - industrial status, grade of occupation, status in employment are terms which have been used interchangeably over time to mean approximately the same thing (e.g. employer of others etc). This makes an analysis of gender in the employment arena a little tricky to nail down. Even in occupations or industries where there appeared more gender equity, the status and roles of men and women were often very different. They still are: for example, taking the Christchurch rebuild as an example, a road-repair gang might have a diverse range of workers but it is usually the older male or the females who get to hold the lolly-pop and direct traffic while the macho young bloods drive the big machines and the boss struts a clip board along the road cones to ensure they are geo-positioned exactly - I am assured that "road cone geopositioning engineer" is a newly emerged profession which can only be done by someone skilled in the use of a clipboard. But things even here are changing quite quickly as skill shortages and labour supply problems bite.

\section{What is re-gendering?}

The first fundamental question: “what is regendering?" At the outset I also need to explain that I am really talking about sex and not gender, because the data I am using is collected by sex. But for once I will bow to the new euphemism to avoid too many circumlocutory knots that I could tangle myself in. So, in this paper, for gender read sex and vice versa, but keep in mind the context within which the data is collected.

Competing theories on re-gendering. On the one hand we have neo-classical with buzzwords like human capital, labour market segmentation theories (institutional processes) and, on the other hand, broadly socio-political theories (where feminism tends to sit because the core is noneconomic in focus). The big problem is that the majority of the work on occupation segregation positions itself in debates centred on pay equality concerns. One consequence of this is that gender goes largely unnoticed and unquestioned.

Arguments that there is work that woman can't do, or men can't do are easily disproved - but they feature large in neo-classical theories and can often be found hidden and disguised in institutionalised segregation. Teaching is a classic example. Primary teaching has become increasingly feminised to the extent that there is genuine concern in the literature for the wellbeing of children because of the absence of men in the profession. Social work and aged care, like education, are industries which are both strongly feminised and hierarchically gendered - though this remains clearer in the professional health sector.

Equality of access does not necessarily translate into equality of uptake or equality of opportunity. Also an under-recognised aspect of gender relations is gender itself - in other words some of the debate seems to imply de-gendering in a sense that seems to fail to recognise that gender is real. Fengshu Liu at a brownbag lecture at UCLA Irvine 6 November 2014 (cf Liu 2013) made a very interesting distinction between the process of degendering and regendering in the duality of an autonomous modern female and a dependent modern female - specifically in the context of China but with strong relevance to western societies as well. It seems that this theme could be unravelled a bit further in the context of gendered labour relations. 
Two quite different themes seem to emerge: (1) the policy-centric view that addressing gender imbalances is a sustainable goal and (2) the processes whereby there are social engineering processes to change gender balance but latent social forces undo these over time. Which of these is dominant changes over time and space, so are intertwined. We need to observe the evidence and think about the demographic and social implications.

What we tend to find is that historically some occupations and industries were strongly gendered and change is slow. Legislative and social pressures can provide influence which leads to some rebalancing of sex ratios in some occupations, there is continuing drift towards inequality at the macro-levels despite these adjustments at micro-levels.

\section{What is non-traditional?}

Non-traditional simply means that an assumption is made on the historical continuities and an observed reality is recognised as not consistent with that assumption.

The main driver in defining something as non-traditional is broad, anecdotal stereotyping, often based on sexist, racial and cultural prejudice. Stereotypes also change over time, sometimes quite dramatically.

Back in 1901 for example, 81 percent of the work force was male. Men and women had their expected places in the employment distribution. Domestic servants were predominantly women, with fewer than 4 percent male. Conversely, fewer than 4 percent of the law clerks, editors, and journalists were female.

By 2013, dramatic changes can be seen, with only 57 percent of the work force now male. Domestic servants have all but disappeared, except in the guise of the in-home care services, which are still predominantly provide by women and an increasing number of male migrant care-givers (Callister et al 2014). Comparing the present with a century ago, 63 percent of law clerks are now female and females have also just taken a majority stake among editors and journalists with 55 percent female.

The growth of the female work force and the change in occupations has forced a redistribution and to some extent a re-gendering of the work force. However, there are still extreme examples of gendered inequalities. For example 94 percent of construction managers are male, while 93 percent of child-care workers are female. All too often the sex ratio of the occupation is reflected in pay discrepancies, however, this pay inequality does not apply in some professions, such as teaching, and in managerial occupations, where women are increasingly outnumbering men.

Observing that 93 percent of shearers are male but 74 percent of shearing shed hands are female not only serves as another example of gendered roles within an industry, but is one that many urban dwellers may not have thought about. Not all work is urban and that rural labour has its own set of gendered roles. 


\section{Why does it matter?}

Richard Anker (2001) in an important review of theories notes that occupational segregation has a detrimental effect on the way men view women and how women view themselves. Mercier (2011) and others have considered this question among women in the mining industry in the US, for example. It can be equally true that the converse applies as the work of people like Pullen, Simpson, and Christie shows when they looked at the relationship between men and so-called feminised occupations (care-giver roles, social work, teaching etc). So a principal question is whether the gender dimension in society at large is related to or differs from the gender dimension of the work force. This is in part what Fengshu was thinking about in a slightly different context - do these two realms exist and operate differently and how exactly are they interconnected?

Why does this matter? Equality, efficiency and social justice are key themes in labour market research and this cuts to the heart of it. People often make a distinction between labour supply (where people prefer to work) and labour demand (who employers prefer). But these "preferences" are learned stances and culturally constrained, so the situation is not as simple as it sounds.

And there are not seamless boundaries between the work force, the labour force and the nonlabour force. This suggests that an important research question is: in what ways are gendered processes in one transferred or influenced by another? While the purpose here is not to answer that question, it does sit quietly as a backdrop to the data.

Another reason why gender and work matters as a theme is related to the observation above that women continue to have lower median incomes in general. But childless women overall have higher incomes than other women and often higher than men. One intriguing connection with another older stream of research is to ask if it is possible to place a valuation on childbearing, and thence to consider whether revisiting the value of children work of the 1980 s may be fruitful.

How gendering is incorporated in analysis matters too. Teresa Ward (2007) has looked at the different roles of qualitative and quantitative data analysis and the extent to which this is gendered. This work builds on work stemming largely from Sandra Harding (1986). Very often we have to use both types of data. Even constructing these as different "types" raises some pertinent questions with respect to scientific method. The devaluation of qualitative data over quantitative data is itself gendered because there is a tendency to privilege the quantitative (masculine) over the qualitative (feminine). This becomes a critical concern because gendering may be camouflaged by inequalities based on birthplace and ethnicity, on the effect of changing age structures, changes in the sex ratio of the work force at large, and the effect of institutional drivers. While much of the analysis is quantitative, this can only be really fleshed out for significance by incorporating a considerable amount of qualitative information

\section{Overview of population change and sex ratio change}


The resident population of New Zealand continues to increase. The salient features are the relationship between the locally born and the overseas born, and the growing dominance of the female population from the 1970 s onwards. The latter is partly related to population ageing, but also to the greater number of men missed from census than women missed. This has been constructed as a "man drought" in the media, but the reality is much more complex (Callister et al, 2006a, 2006b).

People born overseas also contribute to the New Zealand born population with births, but there are losses of New Zealand born and overseas born overseas through emigration and return migration. Changing rates of growth and population aging contributing to shifts in sex ratios. So the proportion born overseas in 2013 is about the same as 1921 but the distribution across occupations differs some occupations and industries highly dependent on migration. Notice current widening gap between male and female for both NZB and OSB.

Figure 1: New Zealand census population, de facto 1901-1971, usually resident 1976-2013, by sex and birthplace (NZ born, overseas born, and birthplace not stated).

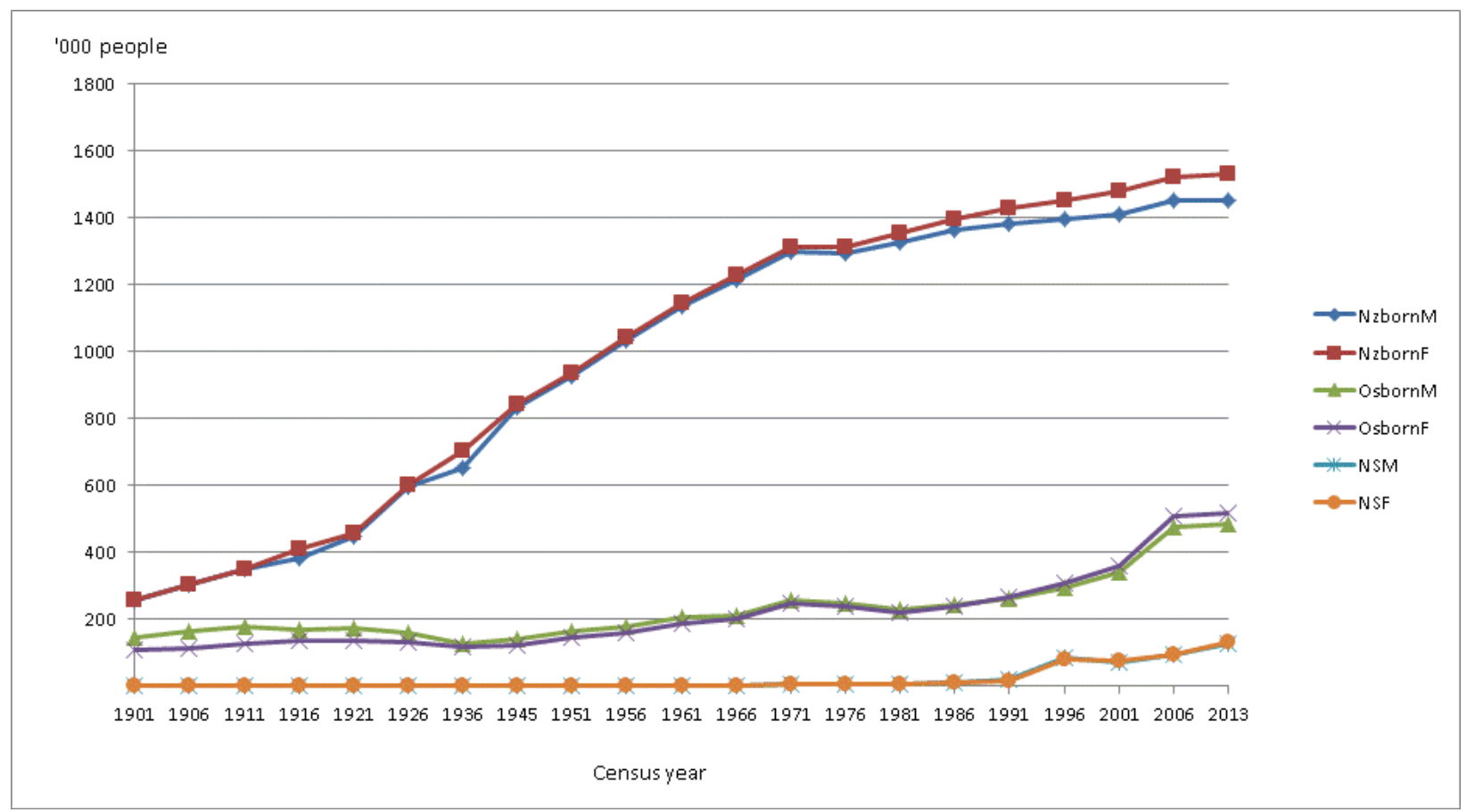

Because gendering in the work force partly depends on labour supply, which is influenced by the relative number of males and females both in the population and in the work force, the sex ratio and how this changes over time provides a quick visual frame within which to work. Figure 2 is a broad picture that includes the same period as figure 1 and the two periods in time referred to in the introduction, viz World War 1 (1914-1918) and the series of 17,000 (and counting) Canterbury earthquakes from late 2010-2013, but further extends the picture out to 2051 to provide a broader context. 
Figure 2: Sex ratio, males per 100 females, New Zealand population, 1901-2051.

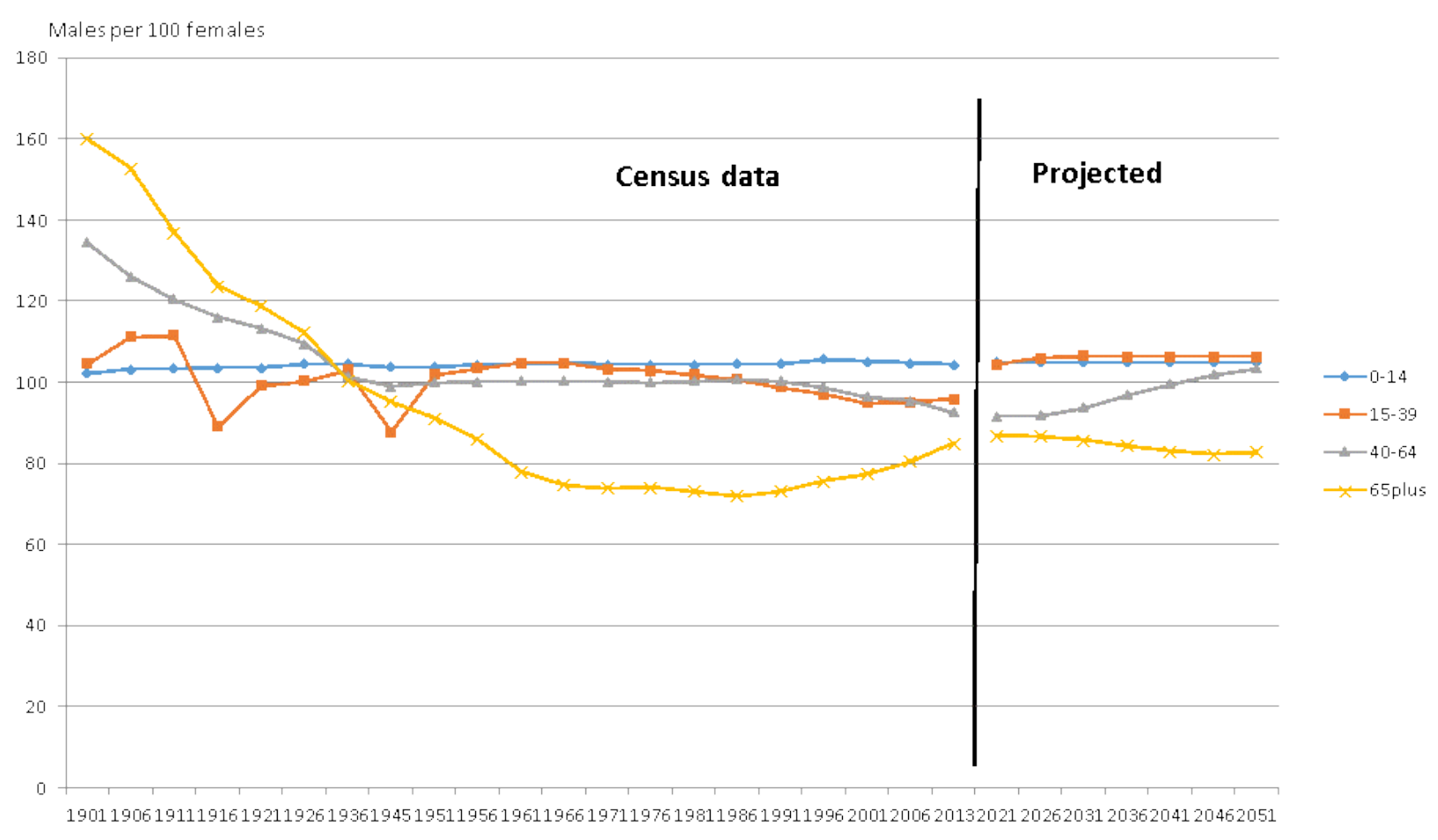

The youngest age group (those under 15 years) has a high sex ratio because more babies are male than female and differential infant and child mortality does not offset this across the age group. Other age groups have moved from high to lower sex ratios over time because of a number of features such as sex ratios in migration flows, gendered differences in enumeration coverage and differential mortality. Differential mortality can be seen most clearly in the periods of the First World War and 1918 influenza epidemic and also in the period around the Second World War for the 15-39 year age group, and also coupled with changes in life expectancy for the older age groups.

Any changes in gendered employment needs to recognise the labour supply implications of changing sex ratios. For example, over the period 1901-1936 there was a rapid feminisation of the population aged 40 years and over, and a lesser shift for the 15-39 year age group. When we compare this with the shifts in sex ratios for those in employment on the same period (figure 3) we find that there was not a commensurate shift in sex ratios for the working population in any of the major occupation groups except for the interlude of World War 1. This suggests that even though the composition of the population was changing the uptake of employment by occupation maintained the same gender structure across the period. So while the number of women increased faster than the number of men, as we see by comparing figures 1 and 2, occupation choices did not change fundamentally.

The period covered by figure 3 covers the historical period from before the First World War, through the war and the false economic flush of the 1920s, with high expectations and rapidly falling fertility up to the end of the Great Depression (1936) just before the "baby boom" kicked in, in 1937-8. 
We see that domestic work continued to attract very few men, resulting in an extremely low sex ratio. However, we also can see that the sex ratio of the professional group, dominated by nursing and teaching also maintained a low, and declining, sex ratio.

Figure 3: Sex ratio, level 1 occupation groups 1901-1936.

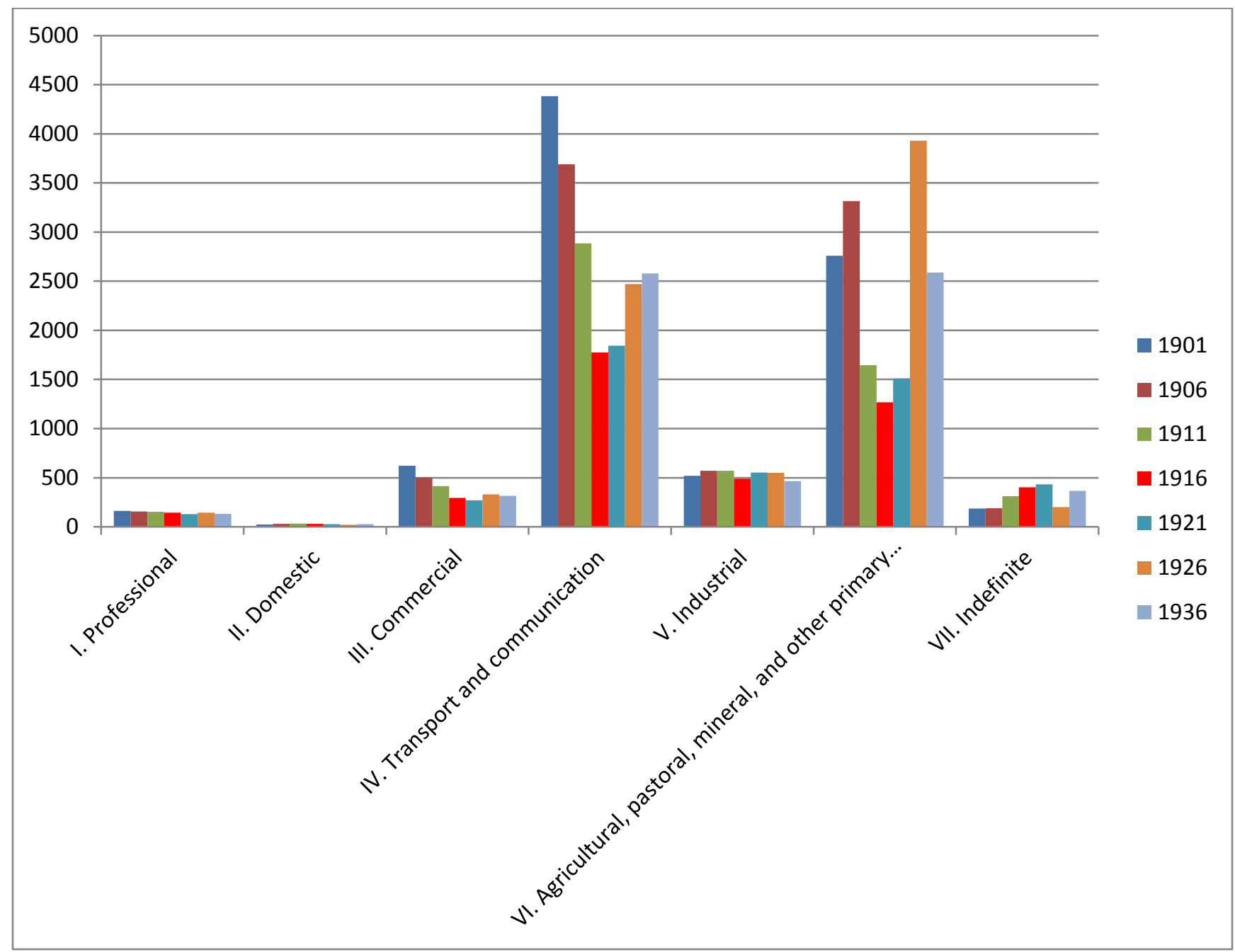

The current interest in women moving into non-traditional work is apposite here. When we look at what happened to the sex ratios for the transport and agriculture sectors, we recognise that we have been in this space before, during World War 1, and there may be key lessons that apply today.

The sex ratio did drop dramatically, however, in transport and agriculture and there was a steady decline in the sex ratios for professional and commercial occupations. But it was temporary. What this shows is that despite the socio-political environment, it was plain that women were largely keeping the seats warm for men and after the war there was massive pressure at the time for women to give up their jobs for the sake of men. The only group with a consistent decline in sex ratio was commercial - and largely this was drawing on those displaced from domestic work as that sector declined in relative terms (though domestic included personal service of other types and in 
fact the numbers continued to climb). Professionals were predominantly female in the lower echelons but males dominated the top levels still (but as a group, the sex ratio was less than half that of the next lowest group, excepting domestic). The point we can draw from this is that there are stories yet to be told by historians. Within industries and occupations there was considerable diversity even in this period. Woollen textile manufacturing, for example, had close to parity by sex, millinery almost entirely female, and shoe manufacturing predominantly male.

\section{WW1 and the myth of feminisation}

The problem is the numbers do not directly bear this out. Partly camouflaging what we are looking at is the fact that the 1916 census was taken before conscription really started to bite in 1916-1918 and before the $1918 \mathrm{flu}$. The numbers underlying the sex ratios in figure 3 provide a clearer picture of what was happening. Sex ratios are reasonably sensitive to differences in rates of change of the components. The sex ratio change for 1916 and 1921 in the transport occupation group, compared with changes in numbers, illustrates this sensitivity well.

Figure 4 shows the number of males in the occupation groups shown in figure 3, while figure 5 shows the females. The scales for males and females are different (the scale for males is 3.5 times larger than the female). The common rhetoric - and I have used this myself - is that the intersection of women's suffrage movements, extension of female rights, international labour movements and the necessities of servicing a war contrived to feminise the work force.

Figure 4: Number of males employed in level 1 occupation groups 1901-1921.

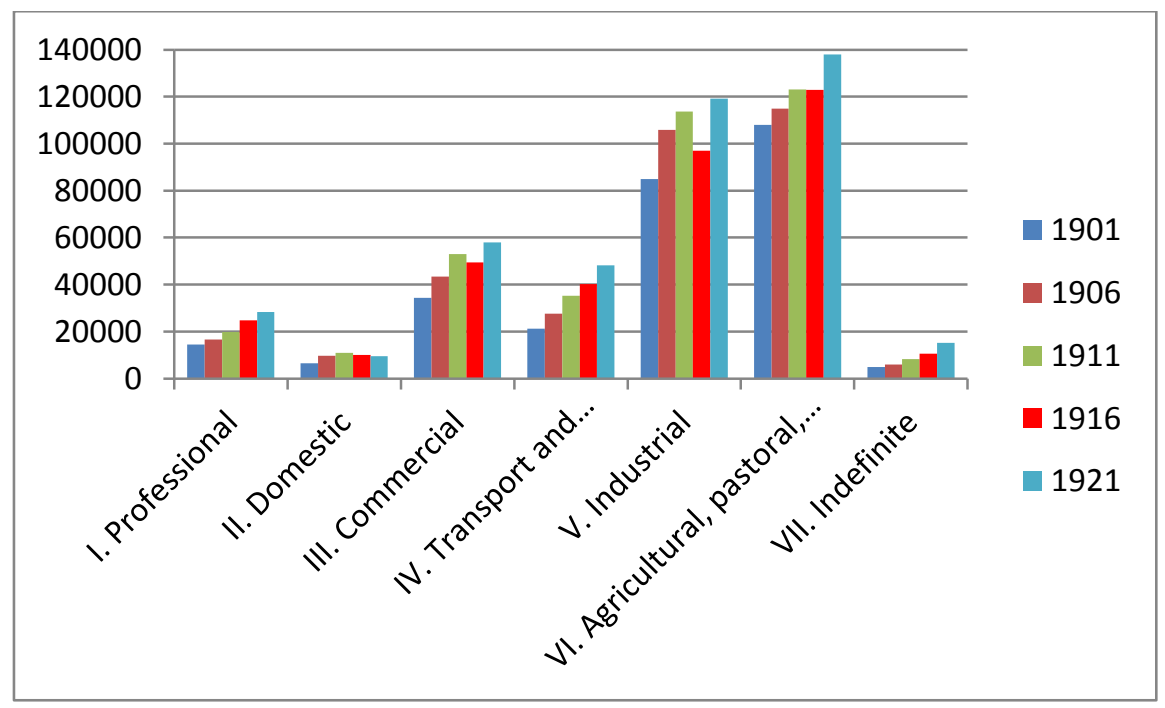

Figure 4 shows that the early part of the war drew men from commercial and industrial occupations predominantly. These are both groups that had sex ratios much lower than transport and agriculture. The 1921 data shows that the pre-war trend had continued despite the 
interruption of war for all groups, with men returning predominantly to their previous occupations. The exception to this pattern was the commercial sector which was at that time becoming more feminised with the emergence of new technologies and women who were wanting to remain employed and were moving to commercial occupations.

Figure 5: Number of females employed in level 1 occupation groups 1901-1921.

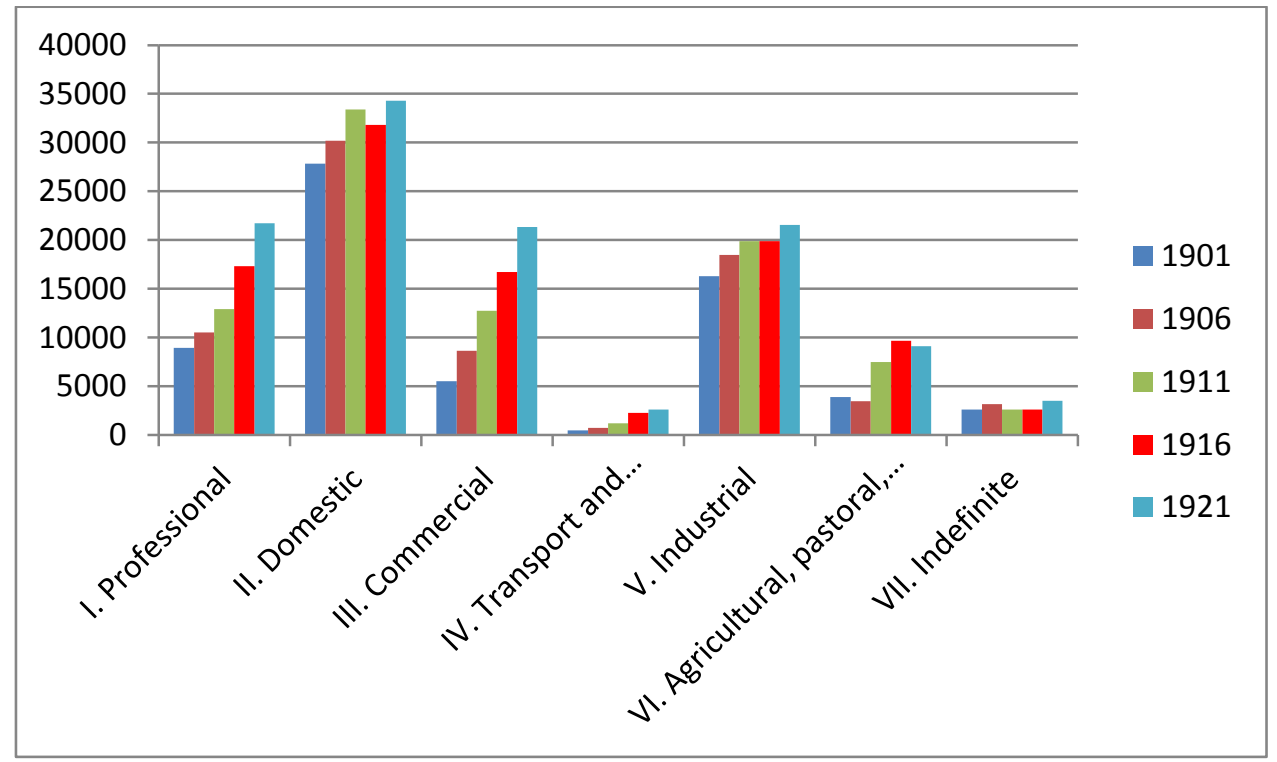

Figure 5 shows that the number of women working in all employment groups rose across the whole period, including in domestic work despite a small decline in numbers in 1916. We also see that the increase in the number of women working in industrial occupations grew consistently across the period with little growth between 1911 and 1916, although withdrawal of men into the military had the effect of dropping the sex ration slightly. Agriculture had also dramatically increased the number of female workers 1960-1911, but here we do see an unsustained increase for 1916 which matches the return of males in 1921. Similarly the increase in transport occupations in 1911-1916 was followed by a period of almost no increase 1916-1921, which contrasts with the steady increase in the number of male workers.

\section{Historical summary of change following World War 1}

Immediately following the war, there was a boom period of reconstruction and burgeoning markets. But this was best described as a fizzled boom. 1919-1920 was a boom period, but the 1920s was one of mixed fortunes which cascaded in the early 1930s into the Great Depression, which had all the hallmarks of being a reprise of the depression of the 1890s.

1936 saw the beginning of recovery and 1937 the beginning of baby boom for the European population. Mãori did not have a baby boom (Pool 1991, Pool et al 2007). This was interrupted by the 1939-1945/6 conflict but continued in the 1950s with the marriage boom. This resulted in large cohorts, with large cohorts of young mothers. The end of the baby boom, usually taken as either 1964 oir 1972 depending on definition, was followed in the 1970s by a rapid decline in fertility for 
all sectors of the population. The 1970s was a period of international economic difficulties and the 1980s onwards characterised by rapid diversification of migration into and out of New Zealand.

Note these are only some of the major formative aspects. The history of each of these features would make an interesting book or thesis. And each of these are topics in their own right. However, they are mentioned here in passing because they are contextually important for the present changes and underlie the current concerns for population ageing, retention of essential skills, attraction of a migrants in an increasingly competitive world, and the gendered transformation of the labour market.

As we noted above, the re-gendering opportunity of offered by World War 1 failed initially because of social forces but then largely because of the lack of momentum. But while fertility dropped consistently over the period, and this should have had the opposite effect of freeing up more women into the labour market, economic conditions were poor and male hegemonies continued. Social conditions still disadvantaged women who may have been career oriented. Generally pregnancy lead to marriage, though abortions were common. Hence, we had the McMillan Report in the late 1930s. This report reflected the pro-natalist view that women who were not having babies were being selfish ( 1 for each other and 1 for the nation!), but it was more significant for the topic here in the insight it gives us to what was considered the norm in gender relations.

From 1936, younger childbearing and increasing family size took more women out of the potential work force but World War 2 reversed that - even more strongly than in the early conflict as women filled employment gaps left by men serving overseas. But again when they returned women war expected to step aside. Younger childbearing remained the norm, but as in 1918-1920, post-war delayed marriages and child bearing produced the large cohorts now found in late careers and contributing to the current concern for population ageing. Similarly the changes since the mid1970s in fertility patterns, migration, family structural changes, and expectations of care and security are all highly gendered processes that have impacts across society.

\section{Century of change}

What difference, then has a century made in the sex ratio within the work force? Figure 6 matches figure 3 so that we can see whether there has been significant change. The two graphs use different classifications, though the occupations have been grouped to be as comparable as possible. Scale also matters. Transport in 1901 had a sex ratio of almost 4,500 males per 100 females and in the 1926 agriculture had almost 4,000 males per 100 females. A hundred years later the sex ratio of even trade occupations, traditionally a highly male dominated sector was under 1,800 males per 100 females.

In early period only domestics had a majority of females. That category has long gone but by 2013 all of the left hand end of the categories from professionals to service/sales have a majority of women and the managers occupation group is close to having majority female (down from 200 males per 100 females in 1991 to 123 by 2013). 
It is very important to note, though, that in the 1901-1936 period the combined group of managers and professionals had dropped from 157 males per 100 females in 1901 to 133 in 1936 (almost entirely because of the professionals in teaching and health, as we currently see). This trend was reversed following World War 2 and has only recently started to continue on the pre-war trend.

Figure 6: Sex ratio, level 1 occupation groups 1991-2013.

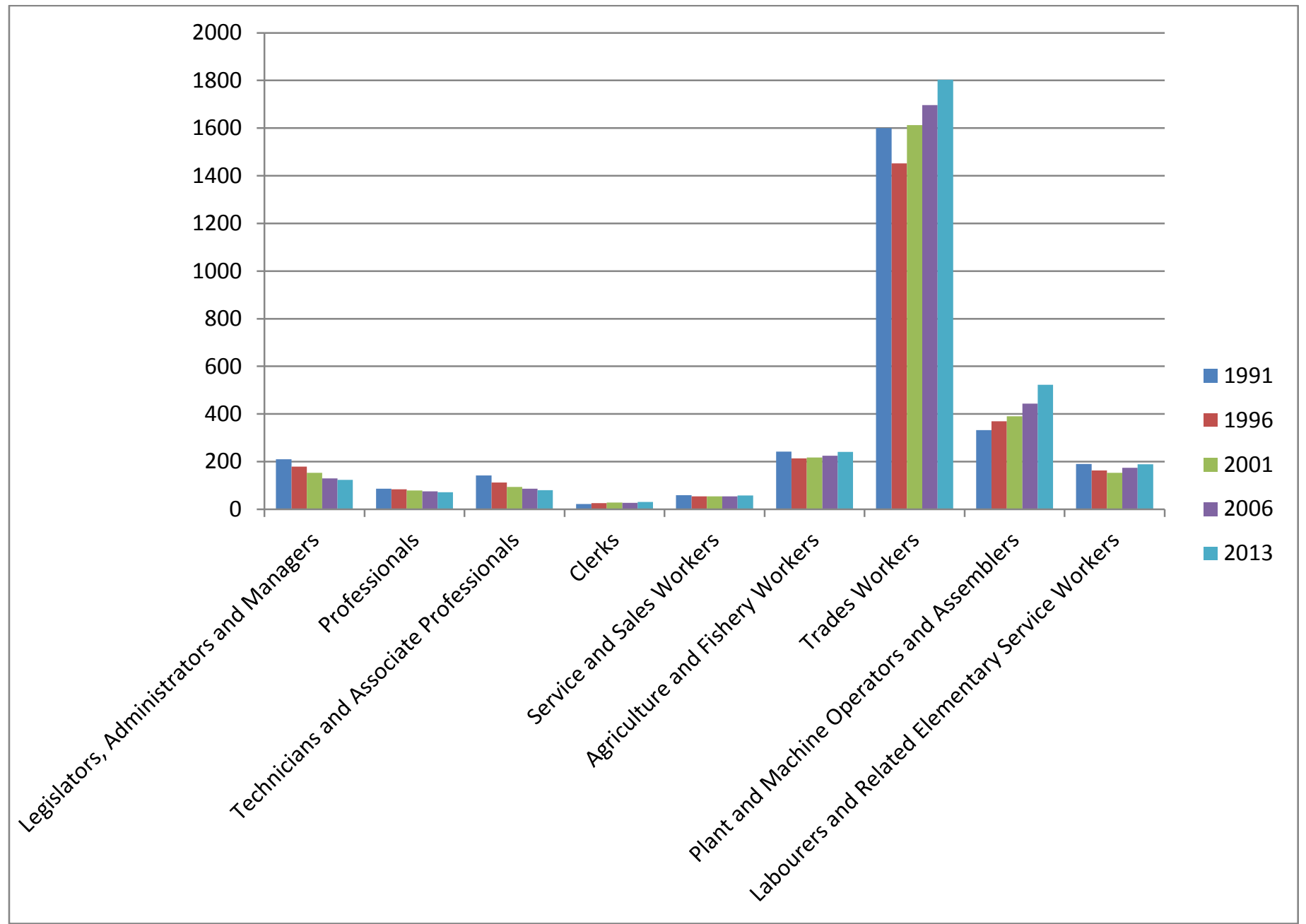

The sex ratio of the agriculture group is interesting because it is now so low compared with what it had been. It has now a tenth of the sex ratio in the earlier period. However, this is largely due to the older age structure of the agricultural work force - working couples on farms especially - and partly a result of the changing levels of mechanisation and intensification in some farming sectors.

This points to a dimension not shown sex ratios for totals: age structures and participation rates vary, and, where couples are working, the relative age of the partners comes into play. Agriculture has some extreme examples of an ageing work force. The number of men in agriculture increases sharply with age. There are 45 percent more males in the sector aged 60-64 years than those aged 20-24 years. But there are 50 percent more males in agriculture who are aged 65-69 years than there are aged 60-64 year old. Clearly a lot change their primary occupation after age 65 (retired as 
farmers, or starting a new career as farmers?) For females in agriculture, there are over twice as many aged 50-54 as aged 20-24 before the numbers starting to drop away, but even those aged 6569 is 80 percent more numerous than those aged 20-24.

\section{Occupational distribution of the work force, by sex, 1996 and 2013}

When we consider change it is not so much the nature of the change but the rate of change that has the greatest impact - and we see this in this very recent short period 1996-2013.

Two points of interest can be seen in figure 7: the change over time and the difference between men and women. For women 1996-2013 there was not only a proportionally smaller percentage of women but there were also numerically fewer women for clerical category as well as for all four bottom categories. For men, only those working in agriculture and fisheries declined in numbers.

For the top 3 categories plus service/sales, women not only increased dramatically but in every case the numerical increase exceeded male increases by a significant margin. Remember that there are only slightly more men than women in the workforce overall (2013 sex ratio is around 110 men per 100 women).

Figure 7: Percentage distribution across level 1 occupation groups, by sex, 1996 and 2013.

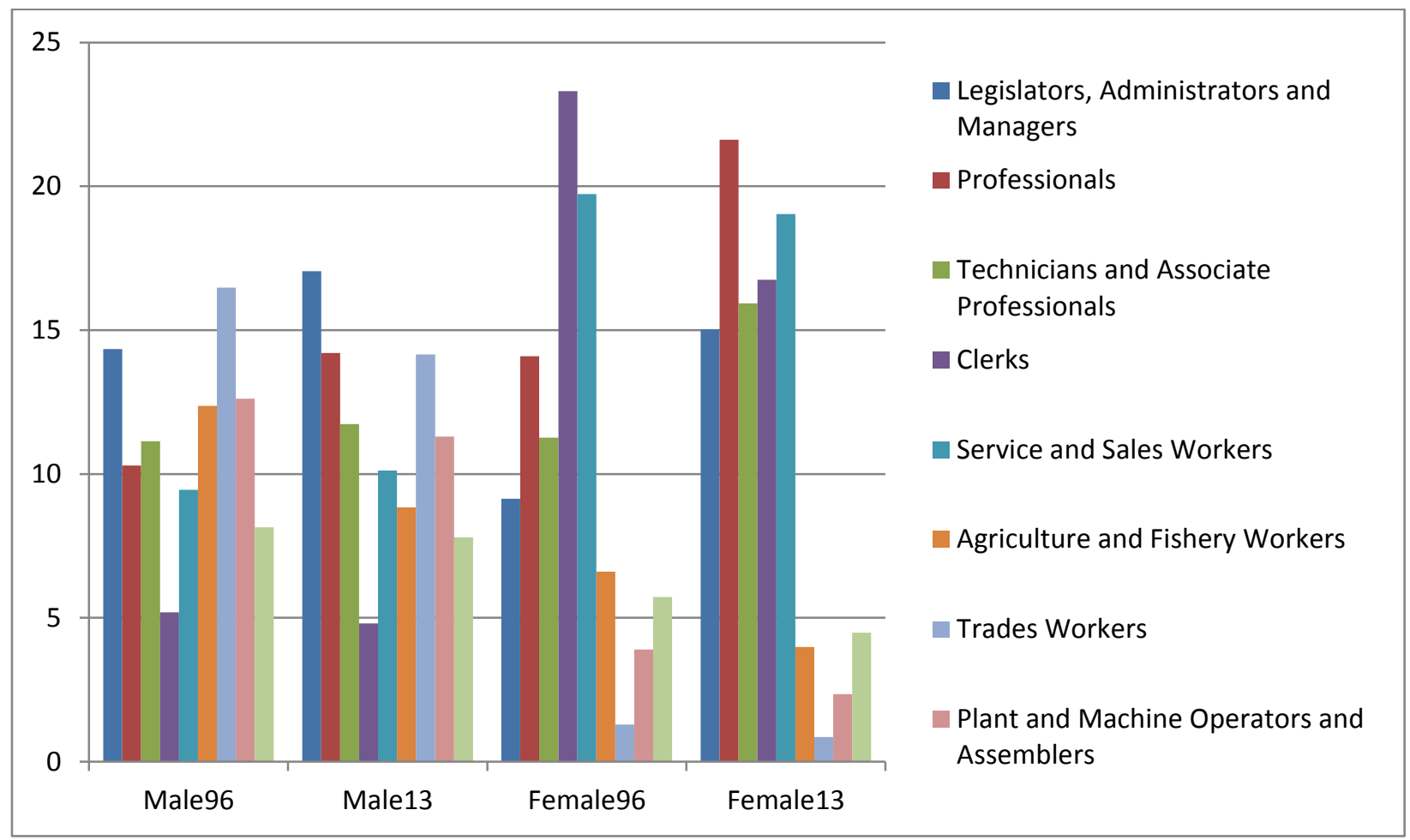


If we look at the distribution of employed men and women by profession we see cases of apparent near equality. If we then look at that by industry we see the apparent equality often melts away. The two extreme examples illustrate that how we measure and what we measure matters.

If we look at the construction industry which is frequently cited as an example of women moving into non-traditional work, we find that there are 612 men for each 100 women. However, in this industry professional occupations account for 5 percent only of the males but 9 percent of the females. This does not equate to saying there are more women than men because there are 6,798 mean and 1,950 women working in professional occupations in the construction industry. However, this shows that women are relatively over-represented in the professional roles.

If we then compare this with the health and care services industry, we find that there are only 22 men per 100 women (or turning the sex ration upside down: 454 women per 100 men). We note that 52 percent of the males in this industry are professionals compared with 45 percent of the women. This could be read as implying that professionals are more likely to be male, but this is not so. Females still outnumber men substantially, with 17,919 males and 69,312 females in professional occupation in the health and care industry.

So there are three important questions:

1. Are those women who are employed and those men who are employed equally represented at all levels within an industry? Often this is so - for example in mining 36 percent of women employed in that industry are either managers or professionals compared with 27 percent of men but women comprise only 300 out of a total workforce in mining of nearly 6,000 . So if we asked if women are getting equal opportunities in mining the superficial answer might be yes they do get to positions of authority. But the bulk of the workforce remains males in the mines, with women in the clerical roles. This is not only a feature of mining in NZ, for similar patterns apply in the US and Canada as Laurie Mercier (2011) has shown.

2. Is equality of opportunity reflected in the sex ratios? This is confounded by a number of things. Equality of opportunity does not necessarily result in equality of uptake. Choice is involved and this implicates social expectations, etc. Above all, we need to ask if there is change over time and if so in what direction?

3. What is the relationship between the full-time employed and the part-time employed, and is this changing?

\section{Gendered concentrations}

Taking the 1986-2013 period to include change: One approach that can show change by gender is to focus on those occupations and industries that have been strongly gendered. If we count the proportion of occupations and industries at the most detailed levels that have more than 90 percent female employees and more than 90 percent male employees in 1986 and see if that proportion has dropped by 2013 we see by that measure that there has been an improvement. We cannot tell 
whether that improvement is continuing to improve or will be sustained - all we can conclude is that there has been a shift in this period.

Figure 8: Occupations and industries dominated by men or women, full-time and part-time employed, 1986 compared with 2013.

\begin{tabular}{|c|c|c|c|c|}
\hline & \multicolumn{2}{|c|}{1986} & \multicolumn{2}{|c|}{2013} \\
\hline & \multicolumn{4}{|c|}{ Occupations } \\
\hline & Full time & Part time & Full time & Part time \\
\hline $\mathrm{N}$ & 1104 & 1055 & 561 & 559 \\
\hline \multicolumn{5}{|c|}{ Percent of employees female } \\
\hline$>=99 \%$ & 1.2 & 8.2 & 0.4 & 2.3 \\
\hline$>=90 \%$ & 4.8 & 16.8 & 3.9 & 9.8 \\
\hline$<=10 \%$ & 43.3 & 24.1 & 29.1 & 14.1 \\
\hline \multirow[t]{3}{*}{$<=1 \%$} & 14.8 & 17.3 & 4.6 & 4.3 \\
\hline & \multicolumn{4}{|c|}{ Industries } \\
\hline & Full time & Part time & Full time & Part time \\
\hline $\mathrm{N}$ & 557 & 550 & 476 & 478 \\
\hline \multicolumn{5}{|c|}{ Percent of employees female } \\
\hline$>=90 \%$ & 0.7 & 14.4 & 0.4 & 3.3 \\
\hline$<=10 \%$ & 18.7 & 3.1 & 9.2 & 0.4 \\
\hline
\end{tabular}

Figure 8 shows the proportion of industries and occupations (at the most detailed level available) which are most extremely gendered, comparing the situation in 1986 with that in 2013. But the devil is in the detail. Of the 8.2 percent of the part-time part-time occupations in 1986 with more than 99 percent female, 82 percent had only females. Similarly of those part-time occupations in 1986 with less than 1 percent female, 98 percent had only male employees. By 2013, 69 percent of those over 90 percent female were only female but all of the 4.3 percent occupations with less than 1 percent female had no females at all. These are mainly in the trades (fitter, welders etc) - and this is worth pondering given the huge efforts being made in getting females into trades training.

Full time occupations also had and still have very low proportions of women in trades occupations. Some might be expected (e.g. grave diggers and stone masons) but others perhaps are a little more surprising (police, geologists, helicopter pilots). There is still very little sign of women making inroads into plumbing, turning and fitting. But there is an indication (builder's labourers for 
example) where part-time work at least are capturing an increasing proportion of female employees.

Similarly some occupations (e.g. midwives) are all women, and have been as far back as we have data. But there are increasing numbers of male registered nurses. Teaching is a problem: in 1986 72 percent of primary teachers were female. By 2013 this had rocketed up to over 83 percent and climbing.

Among the industries, health, care giving, teaching strongly female, but agriculture, mining, fishing are strongly male. In the latter case that if we compare 1986 and 2013 there seems strengthening of this trend even though overall there is greater gender equality in terms of the proportion of industries in the 10-90 percent range (i.e the ones that are not in the extremes shown in figure 8). The interest is in the distribution of those that are slipping out into the extreme ends (particularly where the industries are contracting and women may represent a greater proportion of the losses) compared with those slipping in (e.g. an increasingly wide range of engineering industries are gaining more women, perhaps reflecting success in some of the policy initiatives by agencies such as the Ministry of Women).

To summarise movements in non-traditional work for women:

- Medicine: significantly more GPs are female and this shift is also being reflected in surgery, long a primary male preserve. More surgery graduates are female and similar pattern is seen in most medical specialties, and also in pharmacy.

- Tertiary teaching: in contrast to primary and to a lesser extent secondary, tertiary teaching has not traditionally been seen as a female domain. However, there has been a major shift from around 150 men per 100 women in 1996 to roughly parity in 2013, and females outnumber males in all the younger ages.

- "Hard" sciences: traditionally girls don't do maths, but this is no longer true of those under 40 years of age (and we do not count maths teachers here)

- Engineering: still a major male preserve except for chemical engineering. The biological and environmental sciences also seeing many more females than males coming through, and there are signs of similar patterns in the formal earth sciences.

- Accountants: a surprise - accountancy and law were not long ago intensely male preserves. Again no longer in the younger ages. Female lawyers outnumber males at all ages under 40. As recently as 1996 only the new graduates were more likely to be female. (now 80 percent female)

Christine Williams back in the early 1990s looked at this topic and suggested that there was still power differentials that reflected (as she put it) "Men adopting particular strategies to distinguish themselves from women in order to achieve idealized forms of hegemonic masculinities within occupations that are not traditional for men". And "that men in non-traditional occupations for men are able to maintain coherence between their gender and professional identities and to 'maintain a sense of themselves as different and better than women"' She also noted that in the US 
prior to the civil war these had all been male preserves but by 1900 these had become feminised. So this is not a new phenomenon, but one with interesting sociological roots.

The equal opportunities commissions across Europe more recently became concerned about this because of persistent pay discrepancies and the tendency for men to be more readily promoted. A counter argument here (which Alistair Christie (1998) has pointed to with respect to social work) is that it is so much harder for men to get into these professions and they are under substantially greater scrutiny both during and after appointment, so are more skilled professionally. They also tend to be appointed at managerial and supervisory levels away from the coal face (except in the probation services).

The problem in New Zealand is that in the first two of these non-traditional areas of female employment, men are INCREASINGLY missing.

To summarise movements in non-traditional work for men:

- Primary teaching: fewer than 1 in 10 primary teachers are male, and for some geographic and subject matter areas there are no male teachers at all. There are very very few male Kohanga Reo teachers - this is a concern because there are few enough people with the required language skills as it is. This has important implications for Maori education.

- Social workers: there are no signs of significant improvement here either. Most social workers, probation officers and case workers are female and while the number of males has more than doubled to 5,100, the number of females has very nearly trebled between 1996 and 2013.

- Nursing: this is the slightly bright spot, in the early and mid-career ages (20-49 years) there has been a noticeable increase in the number of male registered nurses and this seems to be a sustained trend. Still the vast majority are female, but for a century or more a male nurse was a rarity.

- Librarians: mostly female traditionally but some indication that more males are becoming librarians. This is also true of archivists.

\section{Changing sex ratios by occupation 1996-2013}

One question that might be asked about the previous discussion of the 1986 to 2013 period is whether the rate of change is changing. Figure 9 shows how the sex ratios for the main occupation groups have changed for the four censuses between 1996 and 2013. This is for the latter part of the previous conversation because this is likely to be where we will find the greater change. Total line is the reference line (black), with groups above the line more male, below more female.

Level 1 of the classification is the most common level of analysis, but we need to be aware that there is massive diversity within the categories. However the graph shows that the machine operator group is becoming very much more male over this period for both full-time and part-time 
employment. Professionals are showing little change. But all other groups are feminising, with the trend among the manager occupations the strongest mover.

Figure 9: Sex ratio changes, level 1 occupations, 1996 to 2013.

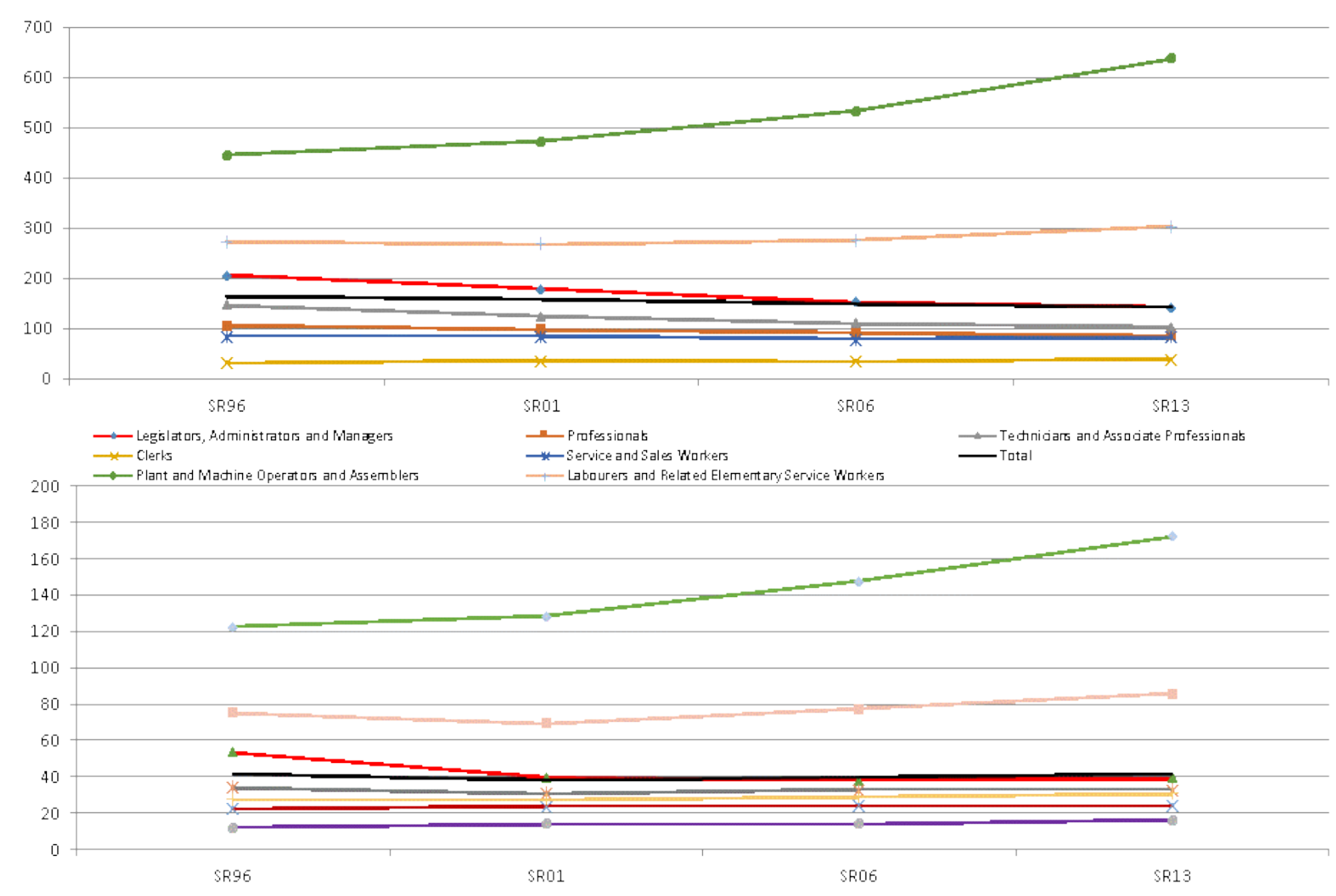

Two examples:

Central govt chief executives: in 1996, of 516 executives, 285 were men (just over half ), but by 2013 of 1,119 651 were men and the sex ratio actually rose slightly - i.e. became more masculine. But for local government chief executives, there was a dramatic difference: in 1996 of the 436 around 75\% (309) were males but by 2013 there were 776 of whom only 1 in 5 (162) were male.

Senior education managers: the number of males was 2,000 in 1996, and this rose to 2,400 by 2013 . But females increased from 1,600 to nearly 5,000 over the same period. In 1996, the number of males exceeded the number of females at all ages from 35 years and over, yet in 2013 all ages had over 60 percent female, and up to 90 percent of those in the younger age groups were female 


\section{Current initiatives}

An investigation of why it was that girls are not considering engineering (E2E - Engineering education to employment) found that there were three central impediments. The first was that engineering as a career option was poorly understood. Partly this derived from the lack of awareness of the gap between trades and graduate engineering. But the over-riding attitude was that engineering was too hard, and those with high levels of mathematics capability had many competing options in mind.

This has partly been addressed by repackaging of trades training in the polytechnics and in some cases (CPIT, for example) offer free courses for women. The reinstatement of some apprenticeship schemes has also helped with New Zealand Apprenticeships open to all aged 16 years and over. However, we still find few females in non-traditional fields.

Current major research to look at barriers to engineering with the objective of increasing annual engineering graduates to 500 from 2015. The focus is on institutes of technology and polytechs, and on addressing the key problem of awareness and preparation - especially in the mathematical sciences. Impediments remain but are recognised as such: the lack of qualified teachers, lack of inspiring courses, lack of awareness of what engineering involves, competing disciplines and specialisation. So many of the key required skills (like calculus) get quarantined into NCEA units that are seen as hard and unattractive. All these are highly gendered issues. There is some progress: to see the rapidity of development we only need to compare the IPENZ reports of 2011 with E2E reports October 2014.

If we look at some current (and this is currently interim provisional data) to see what the tentative numbers look like, we find that essentially half of the painting and decorating enrolments are female. Importantly 20 percent of the welders are female - true this is only 2 out of 10 - but getting welders is seriously difficult and getting good welders nigh on impossible. More importantly a quarter of these enrolments are at level 4 already and the percentage female in these trade courses has risen sharply over 4 years from 4 percent to almost 14 percent. The final numbers won't be out until April or May next year, but they reflect engagement with Youth Transition initiatives, fees for service delivery, managed apprenticeships and represent standard full-time enrolments. Under the Women in Trades Strategy, CPIT had 151 females, of a total 1118 students enrolled in training at CPIT Trades in Semester one 2014. This is 13.5 percent of total enrolments, with an impressive retention shown by the 13.6 percent for the year to date. 
Figure 10: Female enrolments in trades courses, numbers and percentage of headcount for courses, Christchurch Polytechnic Institute of Technology, 2011-2014.

\section{Appendix: Female Enrolments at CPIT Trades 2011-2014}

\begin{tabular}{|c|c|c|c|c|c|c|c|c|}
\hline \multirow[b]{3}{*}{ Programme Cluster } & \multicolumn{8}{|c|}{$\begin{array}{c}\text { Number of Female Students Enrolled } \\
\text { (and \% of total enrolments by headcount) }\end{array}$} \\
\hline & \multicolumn{2}{|c|}{2011} & \multicolumn{2}{|c|}{2012} & \multicolumn{2}{|c|}{2013} & \multicolumn{2}{|c|}{2014 YTD } \\
\hline & Count & $\begin{array}{l}\% \text { of } \\
\text { Total }\end{array}$ & Count & $\begin{array}{l}\% \text { of } \\
\text { Total }\end{array}$ & Count & $\begin{array}{l}\% \text { of } \\
\text { Total }\end{array}$ & Count & $\begin{array}{l}\% \text { of } \\
\text { Total }\end{array}$ \\
\hline Carpentry & 1 & $0.3 \%$ & 11 & $2.0 \%$ & 7 & $1.7 \%$ & 17 & $4.4 \%$ \\
\hline Civil Skills & $\mathrm{n} / \mathrm{a}$ & $\mathrm{n} / \mathrm{a}$ & 1 & $16.7 \%$ & $\mathrm{n} / \mathrm{a}$ & $\mathrm{n} / \mathrm{a}$ & $\mathrm{n} / \mathrm{a}$ & $\mathrm{n} / \mathrm{a}$ \\
\hline $\begin{array}{l}\text { Engineering \& } \\
\text { Electrical }\end{array}$ & 10 & $2.9 \%$ & 13 & $3.9 \%$ & 14 & $5.6 \%$ & 34 & $13.1 \%$ \\
\hline Furniture \& Joinery & 5 & $8.3 \%$ & 3 & $6.7 \%$ & 8 & $22.2 \%$ & 9 & $37.5 \%$ \\
\hline Motor Industry & 8 & $5.9 \%$ & 13 & $7.9 \%$ & 10 & $6.1 \%$ & 11 & $8.0 \%$ \\
\hline $\begin{array}{l}\text { Painting \& } \\
\text { Decorating }\end{array}$ & 22 & $26.5 \%$ & 47 & $25.3 \%$ & 75 & $38.3 \%$ & 75 & $49.0 \%$ \\
\hline $\begin{array}{l}\text { Plumbing \& } \\
\text { Gasfitting }\end{array}$ & 0 & $0.0 \%$ & 1 & $0.6 \%$ & $\mathbf{0}$ & $0.0 \%$ & $\mathbf{0}$ & $0.0 \%$ \\
\hline Retail \& Distribution & 0 & $0.0 \%$ & 5 & $22.7 \%$ & 2 & $33.3 \%$ & 3 & $27.3 \%$ \\
\hline Welding & 3 & $3.0 \%$ & 4 & $4.4 \%$ & 3 & $7.3 \%$ & 2 & $20.0 \%$ \\
\hline Other* & 0 & $0.0 \%$ & 10 & $7.6 \%$ & 1 & $8.3 \%$ & 0 & $0.0 \%$ \\
\hline Total & 50 & $4.2 \%$ & 108 & $6.4 \%$ & 120 & $9.5 \%$ & 151 & $13.5 \%$ \\
\hline
\end{tabular}

Notes

1. "Other" includes Heavy Vehicle, Machinery Operations, Construction (Leading Hand), Masonry and Plasterboard programmes.

2. The "\% of total" figure reflects the number of females enrolled (by headcount), as a percentage of total enrolments in that programme group.

3. The figures in the above table are based on headcount. The contribution by EFTS values indicate similar proportions of female EFTS out of total EFTS.

Much in this area is being driven by the Christchurch Rebuild, which is skill-hungry. Much of the labour is provided by temporary migrant workers and these represent an important skill resource, with some settling permanently. Women moving into non-traditional work has been touted as a key solution, and this has proved very promising. However, this remains still something of a social laboratory. The big question is: what about after the rebuild?

First a question couched as a concern: is Christchurch like World War 1? The city is a bit like a war zone, and we should also remember that greater Canterbury has been affected and the focus on Christchurch largely fails to recognise the massive impacts on the rural and smaller towns.

Skill hungry: major gaps include engineers, builders, and skilled people across the whole social and health spectrum, especially in mental health and poverty management, and we need some good managers with a bit of vision. There are many highly motivated and dedicated people - and most migrants (especially the Filipinos, Indians, Chinese, Indonesians) are praised by the employers. Some others have caused significant social problems, have poor work ethic - a frontier mentality and all too often they are a long way from home. 
Money grants to beneficiaries to move and work for at least 91 days in the same job is from the employers' perspectives more problematic. It gets people off benefits temporarily but is both detrimental to local beneficiaries and to a large extent relocates rather than solves difficulties. Generally this group do the least attractive unskilled work (which, incidentally, is still essential work) so there is a big question mark over their wellbeing and the future social outcomes.

\section{Is there a new traditional}

The idea of a "new traditional" partly stems from a slogan common around Christchurch when we passed the 10,000 earthquake milestone - the "new normal".

Women are filling major gaps at the entry level and moving into previously men-only areas. This is a major positive. The worry is what will happen when the urgency of need diminishes?

There are signs of a new traditional, though to some extent this is because the work force is growing, and in the process is becoming more diverse and more complex. And the female workforce is growing faster with women increasingly in "non-traditional" work.

Men are moving into non-traditional work to a lesser extent. Careers in the professions are increasingly feminised, as are the managerial classes (and it might be valid to refer to class in this context).

The trades are suffering. Men heavily dominate this group, but the re-birth of apprenticeships and trade training is attracting some females who may make careers in the area.

Skill shortages in many occupations. Some areas such as the care industry are dependent on migrants both because of the shortage of a local skill-base and poor working conditions. Other areas such as the highly skilled professional occupations are competing globally for a rapidly shrinking resource pool. These skill shortages are not gender issues, but they become gender issues if equity of access and opportunity are compromised in the process.

However, without the necessity for and sustainability of change, the current apparent re-gendering of the work force may falter as it did a century ago, and this is where we can draw parallels from the past.

One of the more far reaching changes has been among professionals - not only are current professionals increasingly female, in many areas such as medicine and IT the gender imbalance is getting rapidly worse (in these cases in two opposite directions - while nursing is showing some improvement there is an increasing flight of men from the professional areas of medicine - IT is not the growth industry worldwide it once was for many reasons but the loss of women is much greater 
than the loss of men partly because the women are quicker to transfer their skills into other occupations. Nimbleness matters.

So while we can point to significant improvements in areas of technicians and skilled trades we can see rapid re-gendering of some professions away from equality - and in many cases these are different from the imbalance we saw even 30 years ago. To understand the process we do need to take a much deeper time depth so as not to be misled by short-term fluctuations. And we need to look at both improving the opportunities for women and improving the opportunities for men there are areas of the economy where each is disadvantaged for a number of extraneous reasons.

Note that this has been a one-dimensional view - just on gender. Much further work is required to untangle the additional dimensions (such as ethnicity, qualification, country of birth, age and geographic distribution) that may be confounding factors and then put the results fully into demographic context. Then we will be in a position to answer the question: is there a new traditional?

\section{References:}

Anker, R (2001) Theories of occupational segregation by sex: an overview. In: M.l. Loutfi (ed) Women, gender and work. What is equality and how do we get there? Geneva, International Labour Office pp 129-156.

Callister, P., Didham, R. and Bedford, R. (2006b) Changing sex ratios in New Zealand: real change or a statistical problem? New Zealand Population Review 32(1): 21-33.

Callister, P., Bedford, R. and Didham, R. (2006a) Globalisation, gendered migration and labour markets. Department of Labour, Wellington.

Callister, P, Didham R and Badkar, J. (2014) Ageing New Zealand: the growing reliance on migrant caregivers. A 2014 update. Working paper available on www.callister.co.nz

Christie, A. (1998) Is social work a 'non-traditional' occupation for men? British Journal of Social Work, 28: 491-510

Harding, S. 1986. The science question in feminism. New York: Cornell University Press.

Ladner, K. (2008) Gendering decolonization, decolonizing gender. Paper presented at the 80 th Annual Conference of the Canadian Political Science Association, June 2008. Vancouver, University of British Columbia.

Liu, Fengshu (2013) From degendering to (re)gendering the self: Chinese youth negotiating modern womanhood. Gender and Education, 26(1): 18-34.

Martino, W. (2008) Male Teachers as Role Models: Addressing Issues of Masculinity, Pedagogy and the Re-Masculinization of Schooling. Curriculum Inquiry 38(2): 189- 
Mercier, L (2011) Bordering on Equality: Women Miners in North America. In: Kuntala Lahiri-Dutt (ed) Gendering the field: towards sustainable livelihoods for mining in mining communities.: Asia-Pacific environment monographs ; Canberra, ANU Press pp 33-48.

Pool, I (1991) Te iwi Maori. Auckland, Auckland University Press.

Pool, I, Dharmalingam, A, and Sceats, J (2007) The New Zealand Family from 1840. A demographic history. Auckland, Auckland University Press.

Pullen, A. and Simpson, R. (2009) Managing Difference in Feminized Work: Men, Otherness and Social Practice. Human Relations 62(4): 561-587.

Reskin, B and Hartmann, H (1986) Women's work, men's work. Sex segregation on the job. Washington DC, National Academy Press.

Rowan, C (1981) Review of Gail Braybon Women workers in the First World War. Croom Helm 1981. Marxism Today June 1981, 27-28.

Simpson, R (2004) Masculinity at work: the experiences of men in female dominated occupations. Work, Employment and Society 18(2): 349-368.

Ward, T. (2007) Quantifying qualitative data Paper presented at the Association for Institutional Research Annual Forum, Atlanta, Georgia State University

Williams, C (1989) Gender differences at work: women and men in non-traditional occupations. Los Angeles, University of California Press

Williams, C. (1992) The glass elevator: hidden advantages for men in the "female" professions. Social Problems 39(3): 253-267.

Williams (1995) Still a man's world: men who do "women's work" Los Angeles, University of California Press 